\title{
Neural Heterogeneities and the coding of contrast envelopes
}

\author{
M Savard $^{1 *}$, R Krahe $^{2}$, MJ Chacron ${ }^{1}$ \\ From Nineteenth Annual Computational Neuroscience Meeting: CNS*2010 \\ San Antonio, TX, USA. 24-30 July 2010
}

It is well known that higher order neurons respond to contrast envelopes (second order statistics) present in sensory stimuli. These contrast envelopes can be defined as the curve connecting successive peaks in the stimulus and can only be obtained through a nonlinear transformation of the stimulus such as the Hilbert transform. They contain important information that is decoded by the brain: for example, removal of these envelopes from speech severely reduces its intelligibility. While recent studies have shown potential mechanisms by which higher order neurons can acquire sensitivity to contrast envelopes, it is generally thought that peripheral sensory neurons do not respond to them.

Using the electrosensory system of the weakly electric fish as a model we performed extracellular recordings from primary afferents while presenting contrastmodulated random amplitude modulations (AMs) of the fish's quasi-sinusoidal electric field and found that about $45 \%$ of units responded to the time varying contrast envelope. Previous studies have shown that these afferents are spontaneously active and display large heterogeneities in their firing rates and burst firing properties: we therefore investigated whether these heterogeneities are linked to contrast envelope coding. We found that afferents with low spontaneous firing rate responded best to the contrast envelope due to higher levels of rectification. We next investigated the basis of this higher level of rectification using a simple phenomenological model of primary afferent activity. We found that varying levels of intrinsic noise as well as overall bias current in our model could reproduce our experimental results, suggesting that neural heterogeneities can significantly influence contrast envelope coding at the sensory periphery.

\footnotetext{
* Correspondence: melissa.savard@mail.mcgill.ca

${ }^{1}$ Department of Physiology, McGill University, Montreal, Quebec, Canada
}

\section{Author details}

'Department of Physiology, McGill University, Montreal, Quebec, Canada

${ }^{2}$ Department of Biology, McGill University, Montreal, Quebec, Canada.

Published: 20 July 2010

doi:10.1186/1471-2202-11-S1-P175

Cite this article as: Savard et al:: Neural Heterogeneities and the coding of contrast envelopes. BMC Neuroscience 2010 11(Suppl 1):P175.
Submit your next manuscript to BioMed Central and take full advantage of:

- Convenient online submission

- Thorough peer review

- No space constraints or color figure charges

- Immediate publication on acceptance

- Inclusion in PubMed, CAS, Scopus and Google Scholar

- Research which is freely available for redistribution

Submit your manuscript at www.biomedcentral.com/submit
C Biomed Central 